\title{
Landing in zone 0: Is ascending thoracic endovascular aortic repair ready for takeoff?
}

\author{
Martin Czerny, MD, MBA
}

From the University Heart Center Freiburg-Bad Krozingen, Bad Krozingen, Germany.

Disclosures: Author has nothing to disclose with regard to commercial support.

Received for publication Nov 30, 2017; accepted for publication Dec 1, 2017; available ahead of print Jan 20, 2018.

Address for reprints: Martin Czerny, MD, MBA, Department of Cardiovascular Surgery, Albert Ludwigs University Freiburg, Faculty of Medicine, University Heart Center Freiburg-Bad Krozingen, Südring 15, 79189 Bad Krozingen, Germany (E-mail: martin.czerny@universitaets-herzzentrum.de).

J Thorac Cardiovasc Surg 2018;155:1390

$0022-5223 / \$ 36.00$

Copyright $(2) 2017$ by The American Association for Thoracic Surgery

https://doi.org/10.1016/j.jtcvs.2017.12.014

Thoracic endovascular aortic repair (TEVAR) has been rapidly embraced by the surgical community for the treatment of various acute and chronic distal aortic arch and descending thoracic aortic pathologies. If one pays attention to the details of a sufficient landing zone length and of respecting several anatomic details, results have been very encouraging. ${ }^{1}$ As a consequence, the enthusiasm has continued when it comes to the possibility of exploring the treatment of even more proximally located disease processes involving the ascending aorta and finally the aortic root.

The first report in the literature of endovascular treatment of acute type A aortic dissection is now more than a decade old, but the progress in the meantime has been slow. This slowness becomes even more striking when one compares the stagnating development of ascending TEVAR with the rapid development of transcatheter aortic valve implantation technology. 2,3

To be able to understand why the current experience of ascending TEVAR is still limited to case series, one has to understand the fundamental differences between and therefore diametrically opposed requirements in technology when it comes to ascending TEVAR: the primary entry tear is nearly always is in proximity to the sinotubular junction and therefore is close to the coronary offspring; there is no classical landing zone, because nearly each and every type A aortic dissection has a retrograde component at least into the noncoronary sinus (so a sealing zone is the maximum achievable); and undersizing instead of oversizing is needed because the dissecting process causes an acute ascending aortic diameter increase as great s $32 \% .^{4}$ Finally, the only component of the aortic root unaffected by dissection remains the aortic annulus. The marriage of transcatheter aortic valve implantation and TEVAR technology is thus the logical next step in the ability to provide a broader solution for a broader group of patients so that we are better able to address the unique requirements with which the underlying disease processes confront us. ${ }^{5,6}$

This brings us to the value of the study of Roselli and colleagues ${ }^{7}$ in this issue of the Journal, which highlights that

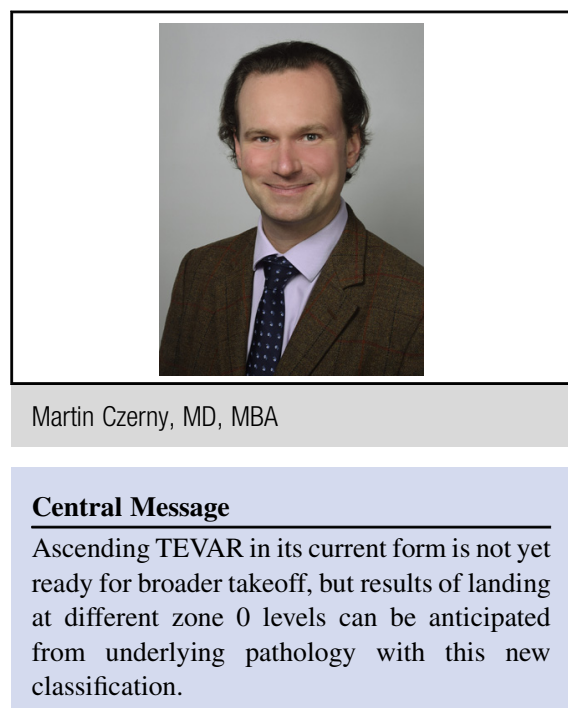

See Article page 1381.

success is dependent on the landing level in the proximal thoracic aorta. In other words, success depends on the underlying disease processes, which affect different proximal aortic segments to different extents, with acute type A aortic dissection being the most complex.

Summarizing, it is desirable and likely that this report will be another stimulus for the aortic community from both the physician and the industry sided to push toward better underlying disease-oriented solutions for a complex but ultimately soluble pathophysiologic challenge.

\section{References}

1. Czerny M, Rodler S, Fakhimi S, Sodeck G, Funovics M, Dumfarth J, et al Midterm results of thoracic endovascular aortic repair in patients with aneurysms involving the descending aorta originating from chronic type B dissections. Ann Thorac Surg. 2010;90:90-4

2. Zimpfer D, Czerny M, Kettenbach J, Schoder M, Wolner E, Lammer J, et al. Treatment of acute type A dissection by percutaneous endovascular stent-graft placement. Ann Thorac Surg. 2006;82:747-9.

3. 2017 ESC/EACTS guidelines on the management of valvular heart disease, Falk V, Baumgartner H, Bax JJ, De Bonis M, Hamm C, Holm PJ, et al. ESC Scientific Document Group. Eur J Cardiothorac Surg. 2017:52:616-64.

4. Rylski B, Blanke P, Beyersdorf F, Desai N, Milewski RK, Siepe M, et al. How does the ascending aortic geometry change when it dissects? J Am Coll Cardiol. 2014; 63:1311-9

5. Rylski B, Szeto WY, Bavaria JE, Branchetti E, Moser W, Milewski RK. Development of a single endovascular device for aortic valve replacement and ascending aortic repair. J Card Surg. 2014;29:371-6.

6. Krüger T, Conzelmann LO, Bonser RS, Borger MA, Czerny M, Wildhirt S, et al. Acute aortic dissection type A. Br J Surg. 2012;99:1331-44.

7. Roselli EE, Idrees JJ, Johnston DR, Eagleton MJ, Desai MY, Svensson LG. Zone zero TEVAR: a proposed modification of the classification of landing zones. $J$ Thorac Cardiovasc Surg. 2018;155:1381-9. 